\title{
Prevalence and costs of treating uncomplicated stage 1 hypertension in primary care:
}

\author{
a cross-sectional analysis
}

\begin{abstract}
Background

Treatment for uncomplicated stage 1

hypertension is recommended in most international guidelines but there is little evidence to indicate that therapy is beneficial.

\section{Aim}

To estimate the prevalence of this condition in an untreated population and the potential costs of initiating therapy in such patients.
\end{abstract}

\section{Design and setting}

Cross-sectional study of anonymised patient records in 19 general practices in the West Midlands, UK.

\section{Method}

Data relating to patient demographics, existing cardiovascular disease (CVD), and risk factors (blood pressure and cholesterol) were extracted from patient records. Patients with a blood pressure of 140/90-159/99 mmHg, no CVD, and $<20 \% 10$-year cardiovascular risk were classified as having uncomplicated stage 1 hypertension. Missing data were imputed. The prevalence of untreated, uncomplicated stage hypertension was estimated using descriptive statistics and extrapolated using national data. The cost of achieving blood pressure control in this population was examined in a cost-impact analysis using published costs from previous studies.

\section{Results}

Of the 34975 patients (aged 40-74 years) in this study, untreated, uncomplicated stage 1 hypertension was present in 2867 individuals (8.2\%, 95\% confidence interval $[\mathrm{Cl}]=7.9$ to 8.5). This is equivalent to 1892519 patients in England and Wales, for whom the additional cost of controlling blood pressure, according to guidelines, was estimated at £106-229 million per annum, depending on the health professional delivering care.

\section{Conclusion}

Untreated, uncomplicated stage 1 hypertension is relatively common, affecting 1 in 12 patients aged 40-74 years in primary care. Current international guidelines and pay-for-performance targets, if followed, will incur significant costs for a patient benefit that is debatable.

\section{Keywords}

antihypertensive agents; cardiovascular disease risk; guidelines; primary prevention.

\section{INTRODUCTION}

Hypertension is a key risk factor for the development of cardiovascular disease (CVD), ${ }^{1}$ the major cause of morbidity and mortality worldwide. ${ }^{2}$ Classifications of hypertension are, by definition, arbitrary and, although most guidelines now include consideration of underlying CVD risk, many recommend pharmacological treatment of blood pressure when it is sustained at $\geq 140 / 90 \mathrm{mmHg}$, regardless of the underlying risk, end organ damage, diabetes, or history of CVD (Table 1).3-13

The treatment of uncomplicated (that is, low risk of CVD) stage 1 hypertension lsustained blood pressure of 140/90$159 / 99 \mathrm{mmHg}$ ) has long been considered controversial due to the paucity of evidence to support such a strategy. ${ }^{14-17}$ A recent Cochrane Review ${ }^{18}$ examined 8912 patients from four clinical trials and found no significant reduction in mortality or cardiovascular events with treatment. Despite these data, new international guidelines and pay-for-performance indicators continue to recommend treatment. 3,4,19 Only guidelines in the UK, Australia, and New Zealand recommend lifestyle advice rather than pharmacological interventions for uncomplicated stage 1 hypertension (Table 1). ${ }^{10-12}$

The impact of these recommendations on clinical practice is unclear. Although the prevalence of hypertension is well

JP Sheppard, PhD, MRC post-doctoral research fellow; RJ McManus, MSc, PhD, DRCOG, FRCGP, NIHR professor, Nuffield Department of Primary Care Health Sciences, University of Oxford, Oxford. K Fletcher, $\mathrm{PhD}$, research fellow, Primary Care Clinical Sciences, University of Birmingham, Birmingham. J Mant, MA, MSc, FFPH, MD, professor, Primary Care Unit, University of Cambridge, Cambridge.

\section{Address for correspondence}

Richard J McManus, Nuffield Department of Primary Care Health Sciences, NIHR School for documented across the world, ${ }^{20-24}$ few studies have examined the prevalence of stage 1 hypertension ${ }^{25,26}$ and none, to the authors knowledge, have examined its prevalence with regard to CVD risk. This study aimed to establish the total number of individuals potentially requiring treatment for uncomplicated stage 1 hypertension, according to international guidelines, in a typical UK primary care population. These estimates were extrapolated to national data $^{27}$ and the cost impact of achieving blood pressure control was quantified in this population using published costs. ${ }^{28,29}$

\section{METHOD}

\section{Data collection}

A cross-sectional retrospective study of anonymised, primary care medical records was conducted in 19 general practices across the West Midlands, UK. The methods of data collection have been detailed elsewhere. ${ }^{30,31}$ Briefly, relevant data were extracted from patient medical records using MIQUEST software. All data queries were run between 17 October 2008 and 6 October 2009; extracted data included:

\section{- demographic information;}

- cardiovascular risk-factor details; and

- all cholesterol and blood pressure lowering medication prescribed within the 90 days prior to the query date.

Primary Care Research, University of Oxford, Oxford OX2 6GG.

E-mail: richard.mcmanus@phc.ox.ac.uk Submitted: 20 February 2014; Editor's response: 8 May 2014; final acceptance: 30 May 2014. (cBritish Journal of General Practice This is the full-length article (published online 29 Sep 2014) of an abridged version published in print. Cite this article as: $\mathbf{B r} \mathbf{J}$ Gen Pract 2014; DOI: 10.3399/bjgp14X681817 


\section{How this fits in}

There are varying recommendations on how to treat people with uncomplicated stage 1 hypertension, but many guidelines recommend therapy for all whose blood pressure is $\geq 140 / 90 \mathrm{mmHg}$, despite the lack of robust clinical trial evidence supporting treatment. At least 1 in 12 patients aged $40-74$ years old have the condition but receive no treatment for it. The cost of initiating treatment in these individuals in England and Wales in line with current international guidelines, would be substantial (€106-229 million: US\$180-389 million and €134-289 million) in the first year, but the benefits for patients are unknown.
This study focused on individuals aged 40-74 years, as younger people require further assessment for secondary causes of hypertension before treatment is administered ${ }^{12}$ and older individuals are likely to fall into the high CVD risk group and, therefore, not be relevant to the research questions addressed here.

\section{Definition of uncomplicated stage 1 hypertension}

This study aimed to establish the prevalence of untreated, uncomplicated stage 1 hypertension. As such, patients with no blood pressure reading from the preceding 5 years, those with existing CVD, or those already receiving blood pressure or cholesterol-lowering therapy were not considered in this analysis; it was assumed that patients receiving blood pressure- or

\section{Table 1. Summary of treatment recommendations for patients with stage 1, 2, and 3 hypertension}

\begin{tabular}{|c|c|c|c|c|c|c|c|c|c|}
\hline \multirow[b]{2}{*}{ Guideline } & \multirow[b]{2}{*}{$\begin{array}{l}\text { Country/ } \\
\text { region }\end{array}$} & \multirow[b]{2}{*}{ Year } & \multicolumn{3}{|c|}{ Low CVD risk } & \multicolumn{3}{|c|}{ High CVD risk ${ }^{a}$} & \multirow[b]{2}{*}{ Notes } \\
\hline & & & $\begin{array}{l}\text { Stage } 1 \\
\text { HT }\end{array}$ & $\begin{array}{l}\text { Stage } 2 \\
\text { HT }\end{array}$ & $\begin{array}{c}\text { Stage } 3 \\
\text { HT }\end{array}$ & $\begin{array}{c}\text { Stage } 1 \\
\text { HT }\end{array}$ & $\begin{array}{c}\text { Stage } 2 \\
\text { HT }\end{array}$ & $\begin{array}{c}\text { Stage } 3 \\
\text { HT }\end{array}$ & \\
\hline $\begin{array}{l}\text { European Society of } \\
\text { Hypertension }\end{array}$ & Europe & 2013 & Therapy & Therapy & Therapy & Therapy & Therapy & Therapy & $\begin{array}{l}\text { Initiate therapy in low-risk stage } 1 \mathrm{HT} \\
\text { if lifestyle modification is unsuccessful }\end{array}$ \\
\hline $\begin{array}{l}\text { Canadian Hypertension } \\
\text { Education Program }\end{array}$ & Canada & 2013 & Therapy & Therapy & Therapy & Therapy & Therapy & Therapy & $\begin{array}{l}\text { Therapy should only be initiated if mean } \\
\mathrm{BP} \text { is raised on three occasions (high } \\
\text { risk or stage } 2-3 \mathrm{HT} \text { ) or five occasions } \\
\text { (stage } 1 \mathrm{HT} \text { and low risk) }\end{array}$ \\
\hline $\begin{array}{l}\text { National Institute for } \\
\text { Health and Care } \\
\text { Excellence }^{12}\end{array}$ & UK & 2011 & $\begin{array}{l}\text { Lifestyle } \\
\text { advice }\end{array}$ & Therapy & Therapy & Therapy & Therapy & Therapy & $\begin{array}{l}\text { Diagnosis of hypertension is based on } \\
\text { a combination of clinic and ambulatory } \\
\text { BP readings }\end{array}$ \\
\hline $\begin{array}{l}\text { National Heart } \\
\text { Foundation of } \\
\text { Australia }^{11}\end{array}$ & Australia & 2010 & $\begin{array}{l}\text { Lifestyle } \\
\text { advice }\end{array}$ & $\begin{array}{l}\text { Lifestyle } \\
\text { advice }\end{array}$ & Therapy & Therapy & Therapy & Therapy & $\begin{array}{l}\text { Treatment is also recommended in } \\
\text { patients with moderate CVD risk } \\
(10-15 \%) \text { and raised } \mathrm{BP}(>140 / 90 \mathrm{mmHg})\end{array}$ \\
\hline $\begin{array}{l}\text { Latin American Society } \\
\text { of Hypertension? }\end{array}$ & Latin America & 2009 & Therapy & Therapy & Therapy & Therapy & Therapy & Therapy & $\begin{array}{l}\text { Therapy should only be initiated in } \\
\text { patients with stage } 1 \text { or } 2 \text { HT if raised } \\
\text { BP persists for 'a few weeks' (in those } \\
\text { with moderate CVD risk) or 'several } \\
\text { months' (in those with low CVD risk) }\end{array}$ \\
\hline $\begin{array}{l}\text { Japanese Society of } \\
\text { Hypertension }\end{array}$ & Japan & 2009 & Therapy & Therapy & Therapy & Therapy & Therapy & Therapy & $\begin{array}{l}\text { Therapy should be initiated in patients } \\
\text { with stage } 1 \mathrm{HT} \text { if raised } \mathrm{BP} \text { is } \\
\text { sustained after a period of lifestyle } \\
\text { modification }\end{array}$ \\
\hline $\begin{array}{l}\text { American Heart } \\
\text { Association }{ }^{5,6,13}\end{array}$ & US & 2006-201 & 4 Therapy & Therapy & Therapy & Therapy & Therapy & Therapy & $\begin{array}{l}\text { JNC8 suggests patients aged } \geq 60 \text { years } \\
\text { should only be treated if BP is } \\
\geq 150 / 90 \mathrm{mmHg}\end{array}$ \\
\hline $\begin{array}{l}\text { New Zealand } \\
\text { Guidelines Group }{ }^{10}\end{array}$ & New Zealand & 2003 & $\begin{array}{l}\text { Lifestyle } \\
\text { advice }\end{array}$ & $\begin{array}{l}\text { Lifestyle } \\
\text { advice }\end{array}$ & Therapy & Therapy & Therapy & Therapy & $\begin{array}{l}\text { Treatment is based solely on CVD risk: } \\
\text { those with high CVD risk should receive } \\
\text { therapy. Stage } 3 \mathrm{HT}=\geq 170 / 100 \mathrm{mmHg}\end{array}$ \\
\hline $\begin{array}{l}\text { WHO/International } \\
\text { Society of Hypertension }{ }^{8}\end{array}$ & World & 2003 & Therapy & Therapy & Therapy & Therapy & Therapy & Therapy & \\
\hline
\end{tabular}




\section{Table 2. Unit costs of treatment and NHS service delivery required to achieve blood pressure control in patients with uncomplicated stage 1 hypertension}

\begin{tabular}{|c|c|c|c|c|c|}
\hline \multirow[b]{2}{*}{ Cost type } & \multirow[b]{2}{*}{ Cost per unit, $€$} & \multicolumn{4}{|c|}{ Annual cost per patient, $€$} \\
\hline & & $\begin{array}{l}\text { Patients requiring } \\
\text { no drugs }\end{array}$ & $\begin{array}{l}\text { Patients requiring } \\
\text { one drug }\end{array}$ & $\begin{array}{l}\text { Patients requiring } \\
\text { two different drugs }\end{array}$ & $\begin{array}{l}\text { Patients requiring } \\
\text { three different drugs }\end{array}$ \\
\hline \multicolumn{6}{|l|}{ Drugs $^{\mathrm{a}}$} \\
\hline Amlodipine 10 mg (28-tablet pack) & 1.07 (1 pack) & 0 & 13.96 & 27.92 & 41.87 \\
\hline Ramipril 10 mg (28-capsule pack) & 1.30 (1 pack) & 0 & 16.96 & 33.92 & 50.87 \\
\hline Indapamide 2.5 mg (28-tablet pack) & 1.40 (1 pack) & 0 & 18.26 & 36.53 & 54.79 \\
\hline Total treatment for a patient aged $<55$ years ${ }^{b}$ & - & 0 & 16.96 & 30.92 & 49.18 \\
\hline \multicolumn{6}{|l|}{ Service deliveryc,d } \\
\hline Practice nurse & 45/hour & 11.25 & 22.50 & 33.75 & 45.00 \\
\hline Nurse specialist & 81/hour & 20.25 & 40.50 & 60.75 & 81.00 \\
\hline GP & 185/hour & 36.00 & 72.00 & 108.00 & 144.00 \\
\hline \multicolumn{6}{|l|}{ Total cost of treatment (aged $\geq 55$ years) } \\
\hline Drug + practice nurse & - & 11.25 & 36.46 & 64.67 & 94.18 \\
\hline Drug + nurse specialist & - & 20.25 & 54.46 & 91.67 & 130.18 \\
\hline \multicolumn{6}{|c|}{$\begin{array}{l}{ }^{a} \text { Costs taken from NHS Electronic Drug Tariff database, correct as of May } 2013.28 \text { b As defined by the National Institute for Health and Care Excellence treatment algorithm. } \\
{ }^{c} \text { Costs of service deliverv given per consultation (unless otherwise statedl based on a face-to-face } 15 \text {-minute nurse consultation or a } 11.7 \text {-minute GP consultation }{ }^{d} \text { Costs ta }\end{array}$} \\
\hline $\begin{array}{l}{ }^{c} \text { Costs of service delivery given per consultation / } \\
\text { from Unit Costs of Health and Social Care 2012. }{ }^{29}\end{array}$ & inless otherwise sta & based on a face-to-fac & 15-minute nurse cons & tation or a 11.7-minute $G$ & PP consultation. ${ }^{d}$ Costs ta \\
\hline
\end{tabular}

\section{Table 3. Characteristics of the study population, $n=34975$}

\begin{tabular}{lc} 
Characteristic & $\boldsymbol{n}(\%)^{\mathbf{a}}$ \\
\hline Female & $16990(49)$ \\
Age, mean (SD) & $54( \pm 10)$ \\
South Asian ethnicity & $1899(12)^{\mathbf{b}}$ \\
Family history of CVD & $4213(12)$ \\
Diabetes & $2598(7)$ \\
Left ventricular hypertrophy & $77(0)$ \\
Chronic kidney disease & $1302(4)$ \\
Myocardial infarction & $733(2)$ \\
Peripheral vascular disease & $487(1)$ \\
Heart failure & $253(1)$ \\
Ischaemic heart disease & $1678(5)$ \\
Stroke & $331(1)$ \\
Transient ischaemic attack & $295(1)$
\end{tabular}

a Unless otherwise stated. ${ }^{b}$ Percentage of 15825 patients in whom ethnicity was recorded. Ethnicity is typically collected by self-report at registration; the relatively low proportions recorded reflect patients who have been registered for some years. $C V D=$ cardiovascular disease. $S D=$ standard deviation. cholesterol-lowering therapy had been at high risk of CVD prior to initiation. ${ }^{12,32}$ The remaining patients formed a potential primary-prevention population and were subdivided on the basis of blood pressure level $\quad<140 / 90 \mathrm{mmHg}=$ normotension; $140 / 90-159 / 99 \mathrm{mmHg}=$ stage 1 hypertension; $\geq 160 / 100 \mathrm{mmHg}$ = stage $2-3$ hypertension) and CVD risk score.

Given that the classification of hypertension was based on only the most recent clinic blood pressure reading, the prevalence of stage 1 hypertension was adjusted to account for the $56 \%$ positive predictive value (PPV) of clinic blood pressure measurements around the diagnostic threshold for hypertension. ${ }^{33}$ The prevalence of stage 2-3 hypertension was not adjusted due to uncertainty about the PPV of blood pressure measurement at higher levels. No attempt was made to impute missing blood pressure data.

\section{Definition of cardiovascular risk status}

Where possible, data on cardiovascular risk factors were used to estimate CVD risk using the Framingham equation. ${ }^{34}$ This risk calculator was recommended by the National Institute for Health and Care Excellence (NICE) ${ }^{35}$ at the time of data collection; it is now recognised, however, that other risk calculators ${ }^{36}$ may be more appropriate for use in UK populations. ${ }^{32}$ CVD risk scores were adjusted by a factor of 1.4 or 1.5 for patients of South Asian origin or a family history of premature cardiovascular events respectively. ${ }^{35}$ Where total or high-density lipoprotein (HDL) cholesterol information was not available, values were imputed using the observed mean cholesterol for patients of the same sex and age group (5-year age bands) with existing cholesterol readings. All other risk factors were assumed not to be present if they were absent from the patient medical records.

\section{Estimation of costs}

The potential costs of treating uncomplicated stage 1 hypertension were examined in a cost-impact analysis using the methodology utilised by NICE for the development of costing tools to assist the implementation of new guidance. ${ }^{37}$ This methodology uses data describing the affected population, the required activity, and the cost of that activity to estimate the financial impact of implementing new guidance on health service budgets. It does not consider these costs in the context of quality-adjusted life years gained, as is the case in a health economic analysis.

The level of new activity generated by guideline implementation was defined in the present study as the number of drugs required to control blood pressure to $<140 / 90 \mathrm{mmHg}$ in each patient and the health professional's time incurred when prescribing and monitoring the treatment regimen. These figures were estimated 
using data from the Hypertension Optimal Treatment trial..$^{38}$ Drug choice was guided by the NICE treatment algorithm, which recommends different combinations of therapy according to patient age and ethnic group. $^{12}$

The costs of resource utilisation were estimated using the NHS Electronic Drug Tariff $^{28}$ (cost of drug prescription) and Unit Costs of Health and Social Care $2012^{29}$ (cost of service provision) (Table 2). This analysis focused on the short-term costs of guideline implementation (first year); it did not consider any possible cost savings resulting from future reductions

Figure 1. Prevalence of hypertension by age and sex

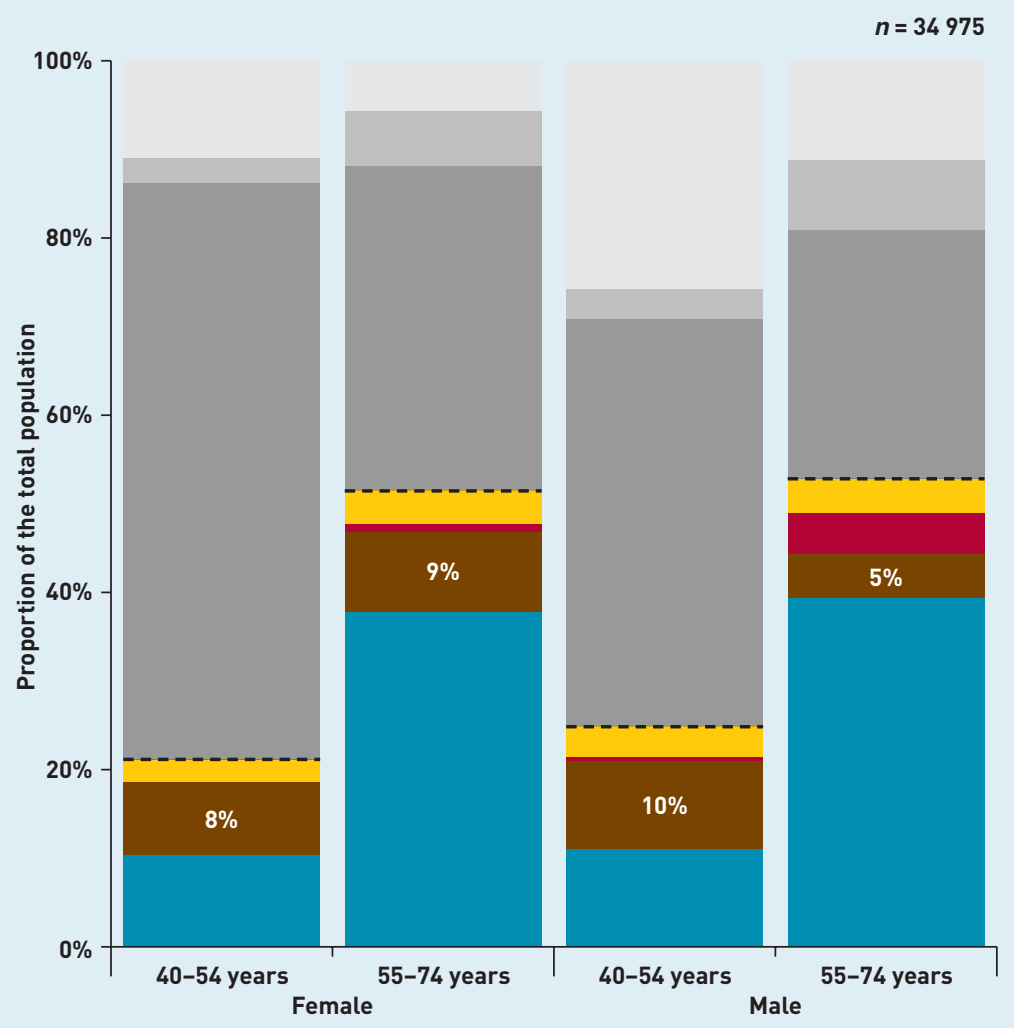

\begin{tabular}{|l|l|}
\hline BP not measured & Untreated stage 2-3 hypertension \\
$\begin{array}{l}\text { Existing CVD or treated high } \\
\text { risk }\end{array}$ & Untreated stage 1 hypertension \\
( $20 \%$ CVD risk) & Untreated stage 1 hypertension \\
Normotension & (<20\% CVD risk) \\
- - Total patients with known & Treated hypertension \\
hypertension & \\
\hline
\end{tabular}

Treated hypertension $=$ patients prescribed antihypertensive therapy. Normotension $=<140 / 90 \mathrm{mmHg}$. Untreated stage 1 hypertension $=140 / 90-159 / 99 \mathrm{mmHg}$. Untreated stage 2-3 hypertension $=\geq 160 / 100 \mathrm{mmHg}$. Prevalence of stage 1 hypertension was adjusted by a factor of 0.56 to account for the $56 \%$ positive predictive value of clinic BP measurements. All patients with a clinic BP of $\geq 160 / 100 \mathrm{mmHg}$ were considered to have stage 2 hypertension due to uncertainty about whether repeated measurement would affect classification at higher BP levels. $B P=$ blood pressure. $C V D=$ cardiovascular disease in cardiovascular morbidity or mortality as it has been argued that such reductions would be minimal in this population. ${ }^{18}$

\section{Analysis}

Descriptive statistics were used to define the proportion of patients in each group with different levels of blood pressure control Inormotension, stage 1, and stage 2-3 hypertension). Data are presented according to age (40-54 years and 55-74 years) and sex; comparisons were made using $\chi^{2}$ tests.

The number of people with untreated, uncomplicated stage 1 hypertension in the population of England and Wales was estimated by extrapolating from the local prevalence estimates derived from this study to national population data. ${ }^{27}$ All data are presented as a mean, \pm standard deviation (SD), and proportion of the total population with $95 \%$ confidence intervals (Cls) (unless otherwise stated). Costs were calculated in pounds sterling and converted to US dollars and euros for comparison purposes. All analyses were carried out using SPSS software (version 21).

\section{RESULTS}

\section{Population characteristics}

Of the 90516 patients registered at participating practices, 34975 were aged 40-74 years and could have been included in this analysis; however, of these, 2550 (7.3\%) patients had existing CVD, 7406 $(21.2 \%)$ were already on treatment, and 4764 (13.6\%) had no clinic blood pressure readings in the preceding 5 years from the data extraction date. Of the remaining 20255 patients (57.9\%), 4985 (14.3\%) had total and HDL cholesterol information available to calculate CVD risk, leaving 15 270 (43.7\%) where cholesterol was imputed. Diabetes, chronic kidney disease, and ischaemic heart disease were the most common comorbidities (Table 3).

\section{Prevalence of untreated, uncomplicated stage 1 hypertension}

A total of 12647 patients had hypertension, of which 4421 patients (35.0\%) were not receiving antihypertensive treatment. In patients receiving no treatment, stage 1 hypertension was present in 3321 individuals $(9.5 \%, 95 \% \mathrm{Cl}=9.2$ to 9.8$)$, of whom 2867 (8.2\%, $95 \% \mathrm{Cl}=7.9$ to 8.5 ) had low $\mathrm{CVD}$ risk (that is, 'uncomplicated'). Untreated, uncomplicated stage 1 hypertension was more common in younger patients (1729 patients, $9.1 \%, 95 \% \mathrm{Cl}=8.7$ to 9.5 [40-54 years] versus 1138 patients, $7.1 \%$, $95 \% \mathrm{Cl}=6.7$ to 7.5 [55-74 years], $P<0.001$ ] and females (1465 patients, $8.6 \%, 95 \% \mathrm{Cl}$ 
Table 4. Costs of treating uncomplicated stage 1 hypertension across the sample and population of England and Wales, according to the health professional delivering treatment

\begin{tabular}{|c|c|c|}
\hline Population & & Cost, $\mathrm{f}^{\mathrm{a}}$ \\
\hline $\begin{array}{l}\text { Sample population, } \\
\text { patients aged } \\
40-74 \text { years }\end{array}$ & $\begin{array}{l}\text { Total, } n \\
\text { Untreated, uncomplicated stage } 1 \text { hypertension, }{ }^{b} n \\
\text { Total cost of treatment if delivered by practice nurse } \\
\text { Total cost of treatment if delivered by nurse specialist }{ }^{c} \\
\text { Total cost of treatment if delivered by GPd }\end{array}$ & $\begin{array}{c}34975 \\
2867 \\
160129 \\
228125 \\
347117\end{array}$ \\
\hline $\begin{array}{l}\text { Population of England } \\
\text { and Wales, patients aged } \\
40-74 \text { years }^{e}\end{array}$ & $\begin{array}{l}\text { Total population, } n \\
\text { Untreated, uncomplicated stage } 1 \text { hypertension, }{ }^{b} n \\
\text { Total cost of treatment if delivered by practice nurse } \\
\text { Total cost of treatment if delivered by nurse specialist }{ }^{c} \\
\text { Total cost of treatment if delivered by GPd }\end{array}$ & $\begin{array}{r}23284217 \\
1892519 \\
105619247 \\
150500331 \\
229042227\end{array}$ \\
\hline
\end{tabular}

anless otherwise stated. ${ }^{b}$ Excludes patients with these conditions for whom blood pressure was not measured within 5 years prior to the study being undertaken. ${ }^{c}$ Nurse appointment based on 15-minute consultation. ${ }^{d} G P$ appointment based on 11.7-minute consultation. ${ }^{e}$ Population in England and Wales is based on data from the Office for National Statistics, mid-year population estimates (2011). ${ }^{27}$ Drug costs from NHS Electronic Drug Tariff database, correct as of May 2013. ${ }^{28}$ Staff costs from Unit Costs of Health and Social Care 2012; unit costs based on the cost of face-to-face contact. ${ }^{29}$ prevalence nationally, it was estimated that approximately 1.9 million people would be affected, with potential annual costs of antihypertensive treatment, if commenced, being £106-229 million (US\$180-389million and €134-289 million).

Initiation of therapy in such patients is not recommended (by guidelines) in the UK but many international guidelines do recommend therapy in this group, ${ }^{3-9,13}$ despite little evidence to suggest it has any benefit. ${ }^{18}$ This study highlights that people with low risk stage 1 hypertension form a significant group for whom more robust evidence of cost-effectiveness is needed prior to commencement of antihypertensive treatment.

\section{Strengths and limitations}

This study used routine data from the West Midlands, UK, and included all registered patients aged 40-74 years from a large cohort of general practices. These data were comparable with the national population aged 35-74 years, in terms of mean age and sex ${ }^{27}$ prevalence of stroke and ischaemic heart disease, diabetes, untreated hypertension, ${ }^{22}$ and mortality. ${ }^{39}$ It was not possible to compare the characteristics of the study population with national trends in ethnicity and social deprivation, and it is acknowledged that results extrapolated from local to national population data should be interpreted with caution.

Data used here were collected in 2008 and 2009 but the researchers are confident that the prevalence estimates are still relevant today. According to figures from the Quality and Outcomes Framework (QOF), ${ }^{19}$ the prevalence of diagnosed hypertension in England has increased very slightly in the past 5 years $10.3 \%$; from $13.4 \%$ to $13.7 \%$ ). The researchers would not anticipate treatment to have changed very much during this period, given that QOF targets have remained largely the same. Although NICE now recommends the use of ambulatory blood pressure monitoring in the diagnosis of hypertension, ${ }^{12}$ this was not expected to greatly influence the present results as prevalence estimates were adjusted to account for the accuracy land variabilityl of clinic blood pressure used in isolation. ${ }^{33}$

The estimates of the prevalence of untreated, uncomplicated stage 1 hypertension presented here may be conservative: patients without a blood pressure reading in the 5 years prior to the study were assumed to not have stage 1 hypertension. Where it was recorded, no correction was made for blood pressure 
measurement error in patients with stage 2-3 hypertension due to uncertainty about the PPV of readings taken around the $160 / 100 \mathrm{mmHg}$ threshold. In practice, there is likely to be a degree of measurement error, resulting in some patients with stage 1 hypertension being classed as having stage 2-3 hypertension and vice versa. The Framingham equation may overestimate risk, resulting in the misclassification of individuals (as high risk) and reducing our estimate of the prevalence of uncomplicated stage 1 hypertension; $;^{40}$ however, this tool was recommended for use in clinical practice by NICE at the time of data collection. ${ }^{35}$

The assessments of CVD risk undertaken were limited to evaluating existing CVD and CVD risk score; target organ damage, and diabetes were not considered separately, although the latter was included in the Framingham risk equation used here. ${ }^{34}$ Therefore, it is possible that a minority of patients may have been classified as low risk when, in practice, most would be treated as high risk. In the case of diabetes, however, only 211 patients were classified as low risk (1.0\%), so the impact of any misclassification is likely to be relatively small. In addition, CVD risk was calculated using cholesterol readings, which were imputed in 15270 patients. This represents a large proportion of the overall sample $(44 \%)$ and there remains the possibility that such an approach may have affected the accuracy of risk estimates and, as such, also the overall estimates of untreated, uncomplicated stage 1 hypertension.

Finally, an assumption was made that there are no long-term benefits from the treatment of uncomplicated stage 1 hypertension, in terms of potential cost savings based on the Cochrane Review findings. ${ }^{18}$ Should this assumption be incorrect, these results will underestimate potential benefit.

\section{Comparison with existing literature}

To the authors knowledge, this is the first study to document the community prevalence of untreated, uncomplicated stage 1 hypertension anywhere in the world. The prevalence of hypertension in international surveys varies by method of diagnosis, and between countries and continents, from $23.0 \%$ to $46.0 \% \%^{20-24,41}$ (depending on the age range of the population studied); the lowest rates have been reported in Canada ${ }^{20}$ and the highest across Africa. ${ }^{23}$ Estimates of untreated hypertension (12.6\%) were comparable with those from previous surveys conducted in Australia (13.1\%), ${ }^{24}$
England (15.8\%), ${ }^{22}$ and Japan (15.9\%). ${ }^{26}$

\section{Implications for research and practice}

This study found that 1 in 12 patients aged 40-74 years have untreated, uncomplicated stage 1 hypertension. The cost of a strategy to treat these patients in clinical practice was estimated to fall between $€ 106$ million and E229 million IUS\$180-389 million or €134-289 million). Whether to initiate treatment in patients with uncomplicated stage 1 hypertension is a source of much debate. ${ }^{14-17}$ The recent Cochrane Review by Diao et $a l_{1}^{18}$ found no evidence that antihypertensive treatment in this population would result in reductions in mortality, coronary artery disease, stroke, or total CVD. Although both the authors of that review and subsequent commentators ${ }^{15}$ point to a lack of power to show benefit, estimates of a number needed to treat (NNT) of 128 for 5 years per cardiovascular event averted suggest few people stand to gain from such treatment. ${ }^{18}$ Indeed, one previous study ${ }^{42}$ suggested that patients judge the maximum acceptable NNT for 5 years to prevent one death in hypertension to be 33 - well below the putative NNT for CVD rather than mortality benefit from treating uncomplicated stage 1 hypertension.

Since the publication of the Cochrane Review, ${ }^{18}$ three guidelines for the management of hypertension have been published:

- The Canadian Hypertension Education Program guidelines ${ }^{4}$ discounted the findings of the Cochrane Review because of the small sample size and cited a 35-year-old non-placebo tria ${ }^{43}$ as justification for maintaining the recommendation to treat uncomplicated stage 1 hypertension (with the caveat that lifestyle modification may be sufficient to control blood pressure without the initiation of therapy). ${ }^{4}$

- The European Society of Hypertension (ESH) guidelines ${ }^{3}$ also note the lack of power in the Cochrane Review ${ }^{18}$ and highlight the paucity of evidence to guide therapy. However, taking into account the limited available evidence ${ }^{44}$ and the low cost and safety of antihypertensive agents, ESH recommends considering blood pressure-lowering therapy in this population.

- The Eighth Joint National Committee guidelines $^{13}$ revised thresholds for treatment such that patients aged $\geq 60$ years should be given treatment if their blood pressure is $\geq 150 / 90 \mathrm{mmHg}$. 
In patients aged $<60$ years, initiation of treatment was encouraged at a threshold of $140 / 90 \mathrm{mmHg}$ (regardless of risk), although it was acknowledged that this recommendation was based on expert opinion alone.

The data presented here do not suggest that therapy to reduce blood pressure in those with low CVD risk and stage 1 hypertension would provide an adequate cost-benefit ratio, given the high NNT and costs in order to prevent one vascular event, along with the potential adverse consequences an individual may experience having been labelled as having hypertension through side effects and labelling. ${ }^{18,45,46}$

Untreated, uncomplicated stage 1 hypertension is common, affecting at least $8.2 \%$ of the population aged $40-74$ years in England and Wales. International guidelines $s^{3-9,13}$ and pay-for-performance targets ${ }^{19}$ encouraging universal thresholds and treatment targets of $<140 / 90 \mathrm{mmHg}$ (regardless of underlying CVD risk) will lead to treatment, with little prospect of benefit at substantial financial cost to healthcare providers across the world. International recommendations should be re-examined to ensure evidence-based treatment until such time as new trials show that benefit outweighs harm and is cost effective. 


\section{REFERENCES}

1. Lewington S, Clarke R, Qizilbash N, et al. Age-specific relevance of usual blood pressure to vascular mortality: a meta-analysis of individual data for one million adults in 61 prospective studies. Lancet 2002; 360: 1903-1913.

2. Ezzati M, Lopez AD, Rodgers A, et al. Selected major risk factors and global and regional burden of disease. Lancet 2002; 360: 1347-1360.

3. Mancia G, Fagard R, Narkiewicz K, et al. 2013 ESH/ESC practice guidelines for the management of arterial hypertension: the task force for the management of arterial hypertension of the European Society of Hypertension (ESH) and of the European Society of Cardiology (ESC). Eur Heart J 2013; 34(28): 2159-2219.

4. Hackam DG, Quinn RR, Ravani P, et al. The 2013 Canadian Hypertension Education Program recommendations for blood pressure measurement, diagnosis, assessment of risk, prevention, and treatment of hypertension. Can J Cardiol 2013; 29(5): 528-542

5. Goldstein LB, Adams R, Alberts MJ, et al. Primary prevention of ischemic stroke: a guideline from the American Heart Association/American Stroke Association Stroke Council: cosponsored by the Atherosclerotic Peripheral Vascular Disease Interdisciplinary Working Group; Cardiovascular Nursing Council; Clinical Cardiology Council; Nutrition, Physical Activity, and Metabolism Council; and the Quality of Care and Outcomes Research Interdisciplinary Working Group: the American Academy of Neurology affirms the value of this guideline. Stroke 2006; 37(6): 1583-1633.

6. Rosendorff C, Black HR, Cannon CP, et al. Treatment of hypertension in the prevention and management of ischemic heart disease: a scientific statement from the American Heart Association Council for High Blood Pressure Research and the Councils on Clinical Cardiology and Epidemiology and Prevention. Circulation 2007; 115(21): 2761-2788.

7. Sanchez RA, Ayala M, Baglivo H, et al. Latin American guidelines on hypertension Latin American Expert Group. J Hypertens 2009; 27(5): 905-922.

8. Whitworth JA. 2003 World Health Organization (WHO)/International Society of Hypertension (ISH) statement on management of hypertension. J Hypertens 2003; 21(11): 1983-1992.

9. Ogihara T, Kikuchi K, Matsuoka H, et al. The Japanese Society of Hypertension Guidelines for the Management of Hypertension (JSH 2009). Hypertens Res 2009; 32(1): 3-107.

10. New Zealand Guidelines Group. The Assessment and Management of Cardiovascular Risk. Wellington: New Zealand Guidelines Group, 2003.

11. National Heart Foundation of Australia (National Blood Pressure and Vascular Disease Advisory Committee). Guide to management of hypertension 2008: assessing and managing raised blood pressure in adults. Updated December 2010. http://uww.heartfoundation.org.au/SiteCollectionDocuments/ HypertensionGuidelines2008to2010Update.pdf (accsessed 27 Jul 2014).

12. National Institute for Health and Care excellence. hypertension: Clinical Management of Primary Hypertension in Adults. 2011. Report No: CG127. http:// unw.nice.org.uk/CG127 laccessd 27 Jul 2014).

13. James PA, Oparil S, Carter BL, et al. 2014 evidence-based guideline for the management of high blood pressure in adults: report from the panel members appointed to the Eighth Joint National Committee (JNC 8). JAMA 2014: 311(5): 507-520.

14. Heath I. Waste and harm in the treatment of mild hypertension. JAMA Intern Med 2013; 173(11): 956-957.

15. Lenzer J. Cochrane review finds no proved benefit in drug treatment for patients with mild hypertension. BMJ 2012; 345: e5511.

16. Ramsay LE, ul Haq I, Yeo WW, Jackson PR. Interpretation of prospective trials in hypertension: do treatment guidelines accurately reflect current evidence? J Hypertens Suppl 1996; 14(5): S187-S194.

17. Toth PJ, Horwitz RI. Conflicting clinical trials and the uncertainty of treating mild hypertension. Am J Med 1983; 75(3): 482-488.

18. Diao D, Wright JM, Cundiff DK, Gueyffier F. Pharmacotherapy for mild hypertension. Cochrane Database Syst Rev 2012; 8: CD006742.

19. NHS Employers, General Practitioners Committee, NHS England. 2013/14 General Medical Services (GMS) contract Quality and Outcomes Framework (QOF): guidence for GMS contract 2013/14. Leeds: NHS Employers, 2013.

20. Robitaille $\mathrm{C}, \mathrm{Dai} \mathrm{S}$, Waters $\mathrm{C}$, et al. Diagnosed hypertension in Canada: incidence, prevalence and associated mortality. CMAJ 2012; 184(1): e49-56.

21. Olives C, Myerson R, Mokdad AH, et al. Prevalence, awareness, treatment, and control of hypertension in United States counties, 2001-2009. PLoS One 2013; 8(4): e60308

22. Boniface S, Bridges S, Craig R, et al. Health survey for England 2011: volume 1 health, social care and lifestyles. http://umw.hscic.gov.uk/catalogue/PUB09300/
HSE2011-Ch1-Intro.pdf (accessed 27 Jul 2014).

23. World Health Organization. Global Status Report on Noncommunicable Diseases 2010: description of the global burden of NCDs, their risk factors and determinants. 2011. http://mmw.who.int/nmh/publications/ncd report2010/en/ laccessed 27 Jul 2014).

24. Appleton SL, Neo C, Hill CL, et al. Untreated hypertension: prevalence and patient factors and beliefs associated with under-treatment in a population sample. $J$ Hum Hypertens 2013; 27(7): 453-462.

25. Gu D, Reynolds K, Wu X, et al. Prevalence, awareness, treatment, and control of hypertension in China. Hypertension 2002; 40(6): 920-927.

26. Nakamura K, Miura K, Nakagawa H, et al. Treated and untreated hypertension hospitalization, and medical expenditure: an epidemiological study in 314622 beneficiaries of the medical insurance system in Japan. J Hypertens 2013; 31(5): 1032-1042.

27. Office for National Statistics. Annual mid-year population estimates for England and Wales, Mid 2011. 2012. http://www.ons.gov.uk/ons/dcp171778_277794.pdf (accessed 27 Jul 2014).

28. NHS Prescription Services. NHS electronic drug tariff. 2013. http://umw.ppa.org.uk/ edt/May_2013/mindex.htm (accessed 9 Sep 2014).

29. Curtis L. Unit costs of health and social care 2012. http://umw.pssru.ac.uk/archive/ pdf/uc/uc2012/full-with-covers.pdf laccessed 27 Jul 2014).

30. Sheppard JP, Singh S, Fletcher K, et al. Impact of age and sex on primary preventive treatment for cardiovascular disease in the West Midlands, UK: cross sectional study. BMJ 2012; 345: e4535.

31. Sheppard JP, Fletcher K, McManus RJ, Mant J. Missed opportunities in prevention of cardiovascular disease in primary care: a cross-sectional study. Br J Gen Pract 2014; DOI: 10.3399/bjgp14X676447.

32. Wierzbicki A, Ahmad R, Banks L, et al. Lipid modification: cardiovascular risk assessment and the modification of blood lipids for the primary and secondary prevention of cardiovascular disease. NICE guidelines (CG181). 2014. http://.www. nice.org.uk/Guidance/CG181 laccessed 9 Sep 2014).

33. Hodgkinson J, Mant J, Martin U, et al. Relative effectiveness of clinic and home blood pressure monitoring compared with ambulatory blood pressure monitoring in diagnosis of hypertension: systematic review. BMJ 2011; 342: d3621.

34. Anderson KM, Odell PM, Wilson PW, Kannel WB. Cardiovascular disease risk profiles. Am Heart J 1991; 121(1 Pt 2): 293-298.

35. National Institute for Clinical Excellence. Lipid modification: cardiovascular risk assessment and the modification of blood lipids for the primary and secondary prevention of cardiovascular disease. Report No: CG067. London: NICE, 2008.

36. Hippisley-Cox J, Coupland C, Vinogradova Y, et al. Predicting cardiovascular risk in England and Wales: prospective derivation and validation of QRISK2. BMJ 2008; 336: 1475-1482

37. National Institute for Health and Care Excellence. Assessing cost impact: methods guide. 2011. http://wnw.nice.org.uk/Media/Default/About/what-we-do/Intopractice/Costing Manual update 050811.pdf (accessed 27 Jul 2014).

38. Hansson L, Zanchetti A, Carruthers SG, et al. Effects of intensive blood pressure lowering and low-dose aspirin in patients with hypertension: principal results of the Hypertension Optimal Treatment (HOT) randomised trial. HOT Study Group. Lancet 1998; 351: 1755-1762.

39. Office for National Statistics. Mortality statistics: deaths registered in England \& Wales. Series DR. 10-5-2012. 2010. http://www.ons.gov.uk/ons/publications/ re-reference-tables.html?edition=tcm\%3A77-230730 laccessed 9 Sep 2014).

40. Neuhauser HK, Ellert U, Kurth BM. A comparison of Framingham and SCOREbased cardiovascular risk estimates in participants of the German National Health Interview and Examination Survey 1998. Eur J Cardiovasc Prev Rehabil 2005; 12(5): 442-450.

41. Kearney PM, Whelton M, Reynolds K, et al. Global burden of hypertension: analysis of worldwide data. Lancet 2005; 365: 217-223.

42. Steel $N$. Thresholds for taking antihypertensive drugs in different professional and lay groups: questionnaire survey. BMJ 2000; 320: 1446-1447.

43. [No authors listed]. Five-year findings of the hypertension detection and follow-up program. I. Reduction in mortality of persons with high blood pressure, including mild hypertension. Hypertension Detection and Follow-up Program Cooperative Group. JAMA 1979; 242(23): 2562-2571.

44. Zhang Y, Zhang X, Liu L, et al. Is a systolic blood pressure target $<140 \mathrm{mmHg}$ indicated in all hypertensives? Subgroup analyses of findings from the randomized FEVER trial. Eur Heart J 2011; 32(12): 1500-1508

45. Hamer M, Batty GD, Stamatakis E, Kivimaki M. Hypertension awareness and psychological distress. Hypertension 2010; 56(3): 547-550

46. Pickering TG. Now we are sick: labeling and hypertension. J Clin Hypertens (Greenwich ) 2006; 8(1): 57-60. 